This item was submitted to Loughborough's Research Repository by the author.

Items in Figshare are protected by copyright, with all rights reserved, unless otherwise indicated.

\title{
Advancing participatory research
}

PLEASE CITE THE PUBLISHED VERSION

https://doi.org/10.14605/RSW121702

\section{PUBLISHER}

Erickson International

VERSION

VoR (Version of Record)

\section{PUBLISHER STATEMENT}

This work is made available according to the conditions of the Creative Commons Attribution-NonCommercialNoDerivatives 4.0 International (CC BY-NC-ND 4.0) licence. Full details of this licence are available at: https://creativecommons.org/licenses/by-nc-nd/4.0/

\section{LICENCE}

CC BY-NC-ND 4.0

\section{REPOSITORY RECORD}

Aldridge, Jo. 2019. “Advancing Participatory Research”. figshare. https://hdl.handle.net/2134/27545. 


\section{Advancing participatory research}

\author{
Jo Aldridge \\ Loughborough University, UK \\ CORRESPONDENCE TO \\ Jo Aldridge \\ e-mail: J.Aldridge@lboro.ac.uk
}

\begin{abstract}
There are both advantages and challenges in conducting research with vulnerable or marginalised populations - people with learning disabilities and mental health problems, children and young people, for example - and it is critical to identify ways of working with these participant groups that promote and enhance their active and meaningful participation. This means ensuring that the methods used in research are genuinely participatory and that are flexible and designed with the needs of participants in mind. It is therefore important that researchers (and practitioners) work with recognised and tried and tested models of participation that advance the rights and needs of vulnerable participants and, more broadly, the PR field. This paper considers the advantages and challenges in conducting participatory research (PR) with vulnerable or marginalised populations, and discusses the utility of a PR model that has been designed specifically for research with participant groups who may be (and, in the past, often have been) overlooked in studies that use conventional methods.
\end{abstract}

Key Words

Participatory Research - Participatory Model - Principles of participation

\section{Introduction}

This paper considers the advantages and challenges in participatory research (PR) in order to advance participatory methods and approaches, specifically with vulnerable or marginalised groups. With this advancement in mind, this paper also considers the need to posit or locate participatory methods more broadly (including participatory action and participatory narrative research - see Chevalier \& Buckles, 2013; Aldridge, 2015) within a defined participatory model (PM). Such a model is constructed and presented (see Figure 1) from a participant-oriented standpoint, and is intended as an aid to researchers (and others) who are planning, or reflecting on the use of, participatory methods with different populations, including vulnerable, marginalised or socially excluded people. The PM 
and associated principles presented and described below are also intended to highlight and promote issues of «voice» and emancipation in qualitative research more broadly. While as Walmsley and Johnson suggest, qualitative research techniques such as case studies, interviews and stories appear to offer opportunities for «increasing power for participants», they also note that'not all qualitative research is concerned with empowering those who take part in it» (2003, p 32).

What is often missing from research that facilitates participatory approaches are guidelines, or a frame of reference, from which researchers (and practitioners) can work in order to enhance collaboration, inclusion and emancipation in research relationships, and particularly with vulnerable or marginalised groups, as well in the processes and practice of PR itself. While the focus of this paper is not on participatory action research (PAR), which tends to focus on large or small group dynamics (Chevalier \& Buckles, 2013, p 10) and community action and transformation, rather than marginalised or socially excluded individuals, nevertheless, some of the underlying principles of PAR are shared with PR more broadly. This is particularly the case in participatory approaches that consider and work with participants as actors in research (see Figure 1) - and especially in terms of «doing research "with people", in lieu of doing it "on them"» (Chevalier \& Buckles, 2013, p 10).

Any proposed participatory framework or model will require commitment from researchers to recognise and adhere to a number of principles and objectives when conducting the kinds of research that make participatory claims, rather than working within a strict set of rules. With respect to the analytical and interpretive phases in PR, strict formulas or techniques should be surrendered in favour of more flexible, and indeed, generous, ways of working with or «reading» data (including narrative, visual or orally produced data). Principles of participation in PR should also ensure greater equity in researcherparticipant relationships (including and particularly when participants are vulnerable, marginalised or socially excluded), and engagement in dialogue with participants as part of an ongoing process throughout the duration of research studies.

Qualitative research methods generally facilitate closer working relationships with human subjects, with the intention of extracting data that reflect this important human dimension in research. Diverse PR studies and methodologies within this qualitative tradition have generated different types of research data, including narratives in the form of personal stories, in visual form, as visual-textual data, as well as in the form of written narratives (Aldridge, 2015). These kinds of methods and approaches that are constructed and articulated as spoken, written or visualised narratives produced by participants themselves in autobiographical form can then serve as «a starting point for developing further understandings of the social construction of each person's subjectivity» (Goodson, 2013, p 30). While it is acknowledged that vulnerable or marginalised groups specifically are often not readily able to access or work with (self-produced) autobiographical methods that result in, for example, published written works, it is also recognised that as a research method, autobiographical techniques (and these can and should also include oral and 
visual methods) «probably [hold] the greatest potential for full and equal partnership» (Walmsley and Johnson, 2003, p 149). This is because such methods and approaches emphasise and promote the participant-as-narrator as the expert or «ultimate insider» (Walmsley \& Johnson, 2003, p 149; Dwyer, 1982; Burgos-Debray, 1984; Kaplan, 1997; Etherington, 2000; Plummer, 2001).

In planning PR projects, whichever method is chosen or deemed to be most suitable, the process of data collection will in every case demand a level of recall and memory performance on the part of participants (Aldridge \& Dearden, 2013), as well as the capacity, and willingness, to translate these recollections into the spoken or written word, or in visual form, as (data) narratives. Thus, the transformative potential of research will depend to a large extent on the appropriateness and efficacy of the research design and methods used.

For some participants, talking about their experiences, in interviews or focus groups, for example, so that these accounts can be recorded and later transcribed, analysed and interpreted as data, will be appropriate and even welcomed. For others, different kinds of data collection methods will be necessary, particularly for those individuals who are more likely to be left out of research altogether, perhaps because they are deemed too difficult to identify and recruit on to studies that use conventional qualitative methods, or because their particular vulnerabilities or needs mean such methods are not appropriate.

The kinds of participatory methods that will be more appropriate for people who are vulnerable or marginalised should allow for a considerable degree of flexibility and creativity in terms of research design and implementation. As well as giving participants opportunities for having a say in the kinds of methods used, PR should also provide them with opportunities for analysing (or co-analysing) and reflecting on the data they produce, the methods used and the participatory experience itself. In some cases, the kinds of methods introduced will provide participants with opportunities for engagement at most if not all of the stages of research production. They may also allow for both participants and their data to «speak for themselves», to some extent, while at the same time offering unique and highly personalised insights into subjective experience.

Sometimes, such insights will raise more questions than answers. For example, where visual data are presented «as is», so to speak (Aldridge, 2015, chapters two and three), or where narratives are produced in full (Aldridge, 2015, chapters four and five), one question might be, do these kinds of approaches, that treat the participant as actor, as «doer» (see Figure 1), tell us something different or unique about the actor (the participant-asresearcher) and their experiences? The aim of participatory or emancipatory research is to confer control over the «telling» and ownership of the data on to participants, and to give them opportunities to present something of themselves as participants, narrators and researchers (and thus to avoid the risk of misinterpretation or misrepresentation). Opportunities for self-enhancement are augmented when participants are more directly involved in research that facilitates autobiographical (self)-elicitation, in whatever form. 
While it is also important to allow participants (as researchers) to engage in analytical and reflexive processes, it is also the case that readers and viewers will, to a large extent, undertake their own interpretations of texts, visual images, and so on, especially where these are presented simply «as is», in which case, it is not always sufficient for participantresearchers to present their data in these ways, although this depends, of course, on the context in which they are produced and made available.

\section{Developing a participatory model}

In considering all of the above issues with respect to PR and working more effectively with vulnerable or marginalised people, we can see the value in shifting to a more personal, individualised approach in order to gain deeper insight into human consciousness, experience and need. The methods used to elicit this kind of information such as autobiography, story-«telling», life histories using oral, written or visual techniques, and other creative methods (Gray \& Sinding, 2002; Sparkes \& Douglas, 2007), as well as reflexive techniques and so on, are best suited to this sort of subjective, individualised approach and to facilitating closer and more collaborative relationships between academic researchers and participants - as well as in practice, between professionals and service users or patients, for example. With respect to social work practice, for example, Baldwin argues:

I believe that social work in its working up of cases, assessments, care plans, reviews and their presentation to supervisors, panels and courts, is essentially a narrative activity...[my interest] draws from literary analysis (using concepts such as genre, plot and characterisation), philosophical undertakings such as rhetorical construction, social structures and identity formation as they emerge and through narrative, and sociological concerns with the work that narratives are called on to do in the wider world $(2013$, p 3).

With regard to PR specifically, it is clear that not all research and practice that adopt participatory methods or techniques lay claim to or align themselves with a strict or clearly defined participatory approach. On the other hand, some PR studies make participatory claims without explicating the nature, extent or limitations of participation involved, and particularly from the perspective of participants themselves. This is clearly unhelpful in terms of promoting and advancing PR as a way of working more effectively with participants, including vulnerable or marginalised individuals or groups. Indeed, researchers, and other interested parties, should not have to search for participatory indicators in descriptions of research studies that claim to use and promote inclusive or emancipatory ways of working. The kinds of participatory methods used, as well as the design and context of the research and the relevant theoretical underpinnings, should be clear from the outset in PR projects, as should the ways in which participatory and, where relevant, emancipatory, principles and objectives will be achieved through working collaboratively and inclusively with participants. 
There are a number of reasons why such clarity is required, not least of which is to avoid research that is tokenistic or simply pays lip service to participatory or emancipatory principles and aims. As Lewis and Porter (2004, p 196) argue, if we are committed to «giving voice» in research, then the process demands «careful planning, preparation and the apportioning of appropriate time», as well as the need to «keep asking ourselves what trust we can place in our methods and check we have not overly predetermined the views that we have encouraged to be heard» (emphasis added).

A further reason is that (academic) researchers must demonstrate commitment, not only to the participants in research (as well as to the academy and to research funders; see Aldridge, 2012), but also to developing and advancing PR methods in order to enhance the credibility and rigour of these kinds of qualitative approaches. We know that studies that use less conventional and more creative methods in qualitative research are not so readily embraced in all contexts - in social policy, for example (Walker et al, 2008). There is therefore even greater need for PR to achieve the kind of rigour and cohesion that has been called for in other related disciplines and fields. In the late 1990s, Lieblich and colleagues proposed that narrative research and methods, for example, required «a deliberate investment of effort in the elucidation of working rules for such studies» (1998, p 1). These same requirements are also relevant today with respect to PAR, for example (Chevalier \& Buckles, 2013) and, I would argue, in terms of PR more generally, but with the emphasis on participatory principles and models of working rather than on strict «rules» or formulas.

A further reason why there is a need for a more cohesive approach to PR based on sound principles and frameworks is that without this there is a danger that unrealistic or even half-hearted attempts will be made to work more collaboratively and inclusively with certain participant groups (including vulnerable or marginalised participants), thus further undermining the credibility of PR methods. This is not to suggest that important advances have not already been made in PR and in working more empathically and inclusively with participants who have traditionally been left out of research studies altogether; having said this, there is perhaps even greater need for care and attention to these matters (that is, to the principles and methods in PR processes) during times of such serious fiscal retrenchment that may mean research studies that are not considered sufficiently «scientific» or «credible» may be at even greater risk of being overlooked in a competitive and increasingly restrictive funding environment.

In such contexts it is even more pressing to try to ensure that vulnerable or marginalised people are included in «mainstream» studies that can also accommodate or allow for a degree of methodological flexibility. Incorporating qualitative methods and, more specifically, clearly defined and designed PR techniques as part of a multi-method approach is one way of achieving this. This would ensure that those who have been left out of, or have had very little input into, research or public policy decision-making processes, could be included in ways that, as Hill and colleagues (2004, p 78) argue, «meet 
their wishes and felt needs» through «multi-dimensional participation». This would help to ensure that vulnerable or marginalised people are included in both research and decision-making processes.

In further considering the ways in which greater clarity and methodological rigour can be brought to PR, what is missing from many studies that make participatory claims, as discussed, is recognition of the nature, extent and limitations of participation within individual projects. While various participatory typologies and models of working have been described and proposed in PAR specifically (see Biggs, 1989; Hart, 1992, 2008; Chevalier and Buckles, 2013), there have been few attempts to evaluate their efficacy, use and relevance in the field, particularly by participants themselves, or to bring these together under a broader PR banner. Neither do many studies that make participatory claims align themselves with specific participatory models or frames of reference.

The PM (see Figure 1) provides a participatory framework for researchers (and professionals/practitioners) to locate their own participatory projects with reference to the various domains within (and across) the model. Drawing extensively on my own experiences of conducting PR or participatory-type projects, as well as evidence from a wide range of other research studies in this field, the PM has been designed for the purpose of helping researchers more clearly align or define their PR projects with reference to, or across, a particular domain or domains within the model itself. The PM (presented from the perspective of participants) allows for a degree of transference between domains, thus some participatory projects may contain elements that traverse or intersect with the different domains.

However, the underlying principle is that research should always move away from tokenistic methods that treat participants as (passive) objects (the «participant as object», $\mathrm{PAO}$, domain in the model in Figure 1), and especially in any kind of research that adopts or lays claim to PR methods and approaches. Thus, the PAO (tokenistic) domain is included in order to serve as a point from which PR should always advance. At the same time it is recognised that it is not always possible for research to be solely or strictly inclusive or «emancipatory» («participant-led», PL) - some research is designed without consultation with participants, but may then involve further elements of participatory design, either through greater collaboration with participants during fieldwork phases or during the outputs phase, for example. Thus, some research may contain participatory elements, where participants are treated as individual subjects («participant as subject», PAS in Figure 1), as well as other participatory elements (across the domains) that facilitate closer collaboration in research processes and relationships (for example, the «participant as actor», PAA, domain). The PL domain prioritises social change outcomes as well as methods and approaches that facilitate and promote participant voice, self-advocacy and emancipation, and that also ensures participants themselves design and lead research projects wherever possible. 
The PM has been designed to provide researchers (and practitioners) with a frame of reference from which they can develop their ideas and plans for working more inclusively with different population groups. As well as providing a measure or guide for future projects, the PM can also be used to evaluate past and current studies and ways of working in professional practice; as stated, the purpose of the PM is to allow for a degree of crossover, or fluidity, within and across the model.

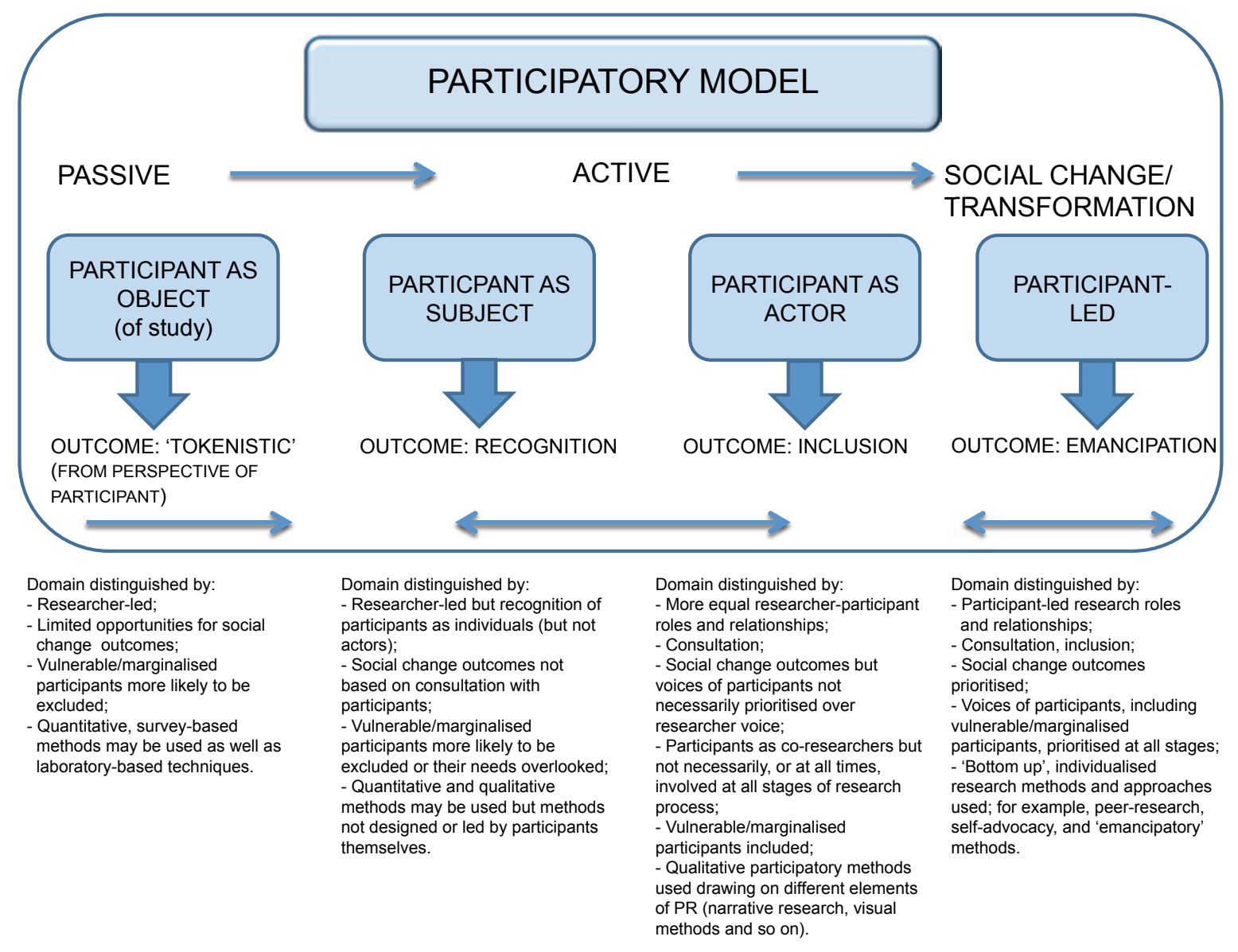

Figure 1

Participatory Model

\section{Principles of participation}

An important aspect of the PM is that it provides researchers with a point of reference and an opportunity to more carefully consider the type of participatory methods and approaches that are possible, and to give greater consideration to the participatory claims that are made in research. Such claims should be verified or validated through careful explanation about the extent and limitations of the specific participatory ap- 
proach adopted in research. Reference to participatory frameworks, typologies or models, such as the PM described in Figure 1, would undoubtedly help in this respect. For those researchers who are thinking about or planning PR, and particularly with vulnerable or marginalised participants, moving away from research that is tokenistic and which treats participants simply as objects and even as subjects in research (the PAO and PAS domains in the PM) would help advance PR methods and approaches that facilitate participant inclusion, collaboration and emancipation. Thus, alongside the PM, the following principles are proposed as a further guide or reference point for researchers (and professionals/ practitioners) when thinking about and planning participatory projects (and particularly at the PAA and PL stages; see Figure 1). In these contexts, PR should:

Be designed with the needs of participants in mind - it should take account of the needs of participants, their conditions and circumstances (including the nature and extent of their vulnerability or marginalisation, as well as social exclusion factors, where relevant).

Involve a process of ongoing dialogue and consultation; this should include discussion of research design issues, the needs and rights of participants, and how «voice» is facilitated and can lead to transformative outcomes, as well as ethical issues and requirements.

Ensure research relationships are based on mutuality, understanding and trust and, depending on the nature and extent of the participatory principles and objectives (what is achievable and realistic in research terms), that the voices of participants are prioritised over those of academic researchers.

Be clear about the opportunities for participation, as well as the extent and limitations of the participatory approach, so that research projects do not raise unrealistic expectations for participants or make false participatory claims. It is essential that PR projects are clearly defined with respect to participatory typologies or participatory models/frameworks.

Ensure participants are given opportunities to reflect on their engagement in research projects, as well as the level/extent or limitations of the participatory methods and approach. In this way, the views of participants must «inform the link between social inclusion and participation» (Hill et al, 2004, p 80). Academic researchers may also want to be reflexive about research processes and relationships in order to make useful contributions to methods debates and discourses.

Be sufficiently flexible so that participatory techniques may be included in larger, mainstream, multi-dimensional studies. PR methods can be effective in studies that adopt multi-method approaches, and this is especially the case when less conventional PR strategies are used, and when working with vulnerable or marginalised people.

Recognise that vulnerability (marginalisation or social exclusion) is both a mutable and contestable concept, and that for most people, vulnerability is not a fixed identity or condition. PR should address vulnerability in this way and attempt to redress the impact of vulnerability or social exclusion, for example, through transformative objectives.

Recognise that transformative outcomes can be personal, social, political, and so on, and may occur immediately, indirectly and/or over time. 
Recognise that data that are collated and/or produced by participants in PR can be subject to different kinds of analyses, interpretation and reflexive processes; these should serve to enhance participant «voice» and ensure that participants are not just treated as the objects of research, but are also considered as co-researchers, collaborators, disseminators, «doers» and self-advocates within what is realistically achievable in PR terms.

\section{References}

Aldridge, J. (2015). Participatory research: Working with vulnerable groups in research and practice. Bristol: The Policy Press.

Aldridge, J. (2012). Working with vulnerable groups in social research: dilemmas by default and design. Qualitative Research, 1-19.

Aldridge, J. (2013). Identifying the barriers to women's agency in domestic violence: the tensions between women's personal experiences and systemic responses. Social Inclusion, 1(1), 3-12.

Aldridge, J. \& Dearden, C. (2013). Disrupted childhoods, in M. Pickering and E. Keightley (eds) Memory research in cultural studies. Edinburgh: Edinburgh University Press, 167-84.

Baldwin, C. (2013). Narrative social work: Theory and application, Bristol: Policy Press.

Biggs, S. (1989). Resource-poor farmer participation in research: A synthesis of experiences from nine national agricultural research systems. OFCOR (On-Farm Client-Oriented Research) Comparative Study Paper 3, The Hague: International Service for National Agricultural Research.

Burgos-Debray, E. (1984). I, Rigoberta Menchú: An Indian woman in Guatemala. (translation by Ann Wright). London: Verso.

Chevalier, J.M. \& Buckles, D.J. (2013). Participatory action research: Theory and methods for engaged enquiry. Abingdon: Routledge.

Dwyer, K. (1982). Moroccan dialogues: Anthropology in question. Baltimore, MD: The Johns Hopkins University Press.

Etherington, K. (2000). Narrative approaches to working with adult male survivors of child sexual abuse: The client's, the counsellor's and the researcher's story. London: Jessica Kingsley Publishers.

Goodson, I.F. (2013). Developing narrative theory: Life histories and personal representation. Abingdon: Routledge.

Gray, R. \& Sinding, C. (2002). Standing ovation: Performing social science research about cancer. Walnut Creek, CA: Altamira Press.

Hart, R.A. (1992). Children's participation from tokenism to citizenship. Florence: UNICEF Innocenti Research Centre (www.freechild.org/ladder.htm).

Hill, M., Davis, J., Prout, A. \& Tisdall, K. (2004). Moving the participation agenda forward. Children \& Society, 18(2), 77-96.

Kaplan, I. (2008). Being "seen" being "heard": engaging with students on the margins of education through participatory photography, in P. Thomson (ed) Doing visual research with children and young people. Abingdon: Routledge, 175-91.

Lewis, A. \& Porter, J. (2004). Interviewing children and young people with learning disabilities: guidelines for researchers and multi-professional practice. British Journal of Learning Disabilities, 32(4), 191-7.

Lieblich, A., Tuval-Mashiach, R. \& Zilber, T. (eds) (1998). Narrative research: Reading, analysis, and interpretation. London: Sage.

Plummer, K. (2001). Documents of life 2: An invitation to a critical humanism. London: Sage.

Sparkes, A.C. \& Douglas, K. (2007). Making the case for poetic representations: an example in action. The Sport Psychologist, 21(2), 170-90. 
Walker, R., Schratz, B \& Egg, P. (2008). Seeing beyond violence: visual research applied to policy and practice', in P. Thomson (ed) Doing visual research with children and young people. Abingdon: Routledge, 164-74.

Walmsley, J. \& Johnson, K. (2003). Inclusive research with people with learning disabilities: Past, present and futures. London: Jessica Kingsley Publishers.

Aldridge, J. (2017). Advancing participatory research.

Relational Social Work, 1(2), 26-35

doi: 10.14605/RSW121702

cc) () $\ominus$ Relational Social Work is licensed under a Creative Commons Attribution-

cc) NonCommercial-NoDerivatives 4.0 International License 